\title{
Innovation and instrumentation: Endovascular repair of the aortic arch
}

\author{
Joseph S. Coselli, MD, and Susan Y. Green, MPH
}

Haulon and colleagues ${ }^{1}$ have long been at the forefront of endovascular technology and should be commended for reporting their evolving experience with double-branched endovascular aortic arch repair (EAAR). Currently, there are several competing strategies for complete EAAR (which involves at least 2 branching vessels of the aortic arch) that use a variety of experimental devices (eg, custom-made branched or fenestrated devices, large-diameter baremetal stents, multilayer flow modulators) and experimental applications of existing, approved devices (eg, paralleldevice approaches [eg, snorkels, periscopes, chimneys] and ad hoc fenestration of standard devices in situ). The literature abounds with case reports, small series, and creative approaches. In this publication, the authors present the largest series $(n=38)$ of double-branched EAAR to date. Much can be learned from their global, multicenter experience using these custom-fabricated, inner-branched devices electively in high-risk surgical patients.

These authors ${ }^{1}$ have been intimately involved with the development of branched and fenestrated endovascular approaches to thoracoabdominal aorta aneurysm repair and perhaps consider EAAR the natural progression of endovascular technology. However, the local environs of thoracoabdominal aorta aneurysm repair and EAAR are different in terms of pulsatility, elasticity, mobility, and curvatureeven these seasoned experts found a perilously steep learning curve while transitioning this technology to the aortic arch. An important early improvement was the shift from cuffs ${ }^{2}$ to inner branches to be used with bridging stents. In their analysis, the authors chose to compare the first 10 cases with the last 28 , both to indicate significant improvement over time and to set reasonable expectations for clinical outcomes in these high-risk patients. Whereas the overall 30 -day mortality rate was $30.0 \%$ in the first 10 cases, it was an improved $7.1 \%$ in the latter 28 ; these results rival the best contemporary open arch results. ${ }^{3,4}$ Despite procedure-related aortic manipulation and the risk of low cerebral flow during implantation, there were only 2 cases

From the Division of Cardiothoracic Surgery, Michael E. DeBakey Department of Surgery, Baylor College of Medicine, Houston, Tex; Texas Heart Institute, Houston, Tex; and Baylor St Luke's Medical Center, Houston, Tex.

Disclosures: Dr Coselli serves as a consultant for Vascutek Terumo. The other author

has nothing to disclose with regard to commercial support.

Received for publication March 26, 2014; accepted for publication March 27; available ahead of print April 24, 2014

Address for reprints: Joseph S. Coselli, MD, One Baylor Plaza, BCM 390, Houston,

TX 77030 (E-mail: jcoselli@bcm.edu).

J Thorac Cardiovasc Surg 2014;148:1717-8

$0022-5223 / \$ 36.00$

Copyright (C) 2014 by The American Association for Thoracic Surgery

http://dx.doi.org/10.1016/j.jtcvs.2014.03.050
$(5.2 \%)$ of stroke and 4 cases $(10.5 \%)$ of transient ischemia. Somewhat surprisingly (given the proximal landing in zone 0 ), there was no retrograde aortic dissection.

There are many interesting facets to this report. Over time, it appears the study parameters were loosened to include patients with extensive chronic aortic dissection (0/10 vs $10 /$ 28 ) or previous ascending aortic replacement (0/10 vs $12 /$ 28); theoretically, landing in non-native aortic tissue could benefit patients by reducing the likelihood of retrograde dissection. Patients with ascending aortas dilated to more than $38 \mathrm{~mm}$ were recruited in both the early and latter cases (4/10 and 7/28); analysis identified diameters exceeding 38 $\mathrm{mm}$ as a significant risk factor for early mortality and neurologic events. From previous reports ${ }^{2}$ of double-branched EAAR, we know that distal stent-grafting was performed in two thirds of patients to treat more extensive aortic pathology (this is unsurprising because isolated aortic arch pathology is uncommon) and that EAAR was problematic in patients with bovine arches. Somewhat troubling was the inclusion of a patient with a mechanical aortic valve, which required the authors to substantially deviate from their typical approach and later resulted in conversion to open surgery. Of note, endoleaks developed in more than one third of patients, including 5 early and 1 late type I endoleak. Introduced risks include the risk of kinking leading to functional coarctation (in patients with steep angles at prior ascending anastomotic sites) and the development of aortic valve regurgitation (possibly related to manipulation during deployment). The follow-up period was relatively short (median, 12 months), and additional analysis is proposed.

However, the authors ${ }^{1}$ appear to overstate the chief risks associated with open aortic arch surgery-operative mortality and stroke-as ranging from $2 \%$ to $16.5 \%$ and $2 \%$ to $18 \%$, respectively, and cite as source material a summary table of outcomes as presented within a review by Moon et $\mathrm{al}^{5}$ and a contemporary report from Iba et al. ${ }^{3}$ The upper limit of the mortality rate $(16.5 \%)$ does not reflect contemporary outcomes because the data were collected between 1978 and 1997, and the upper limit of the stroke rate $(18.0 \%)$ stems from a subgroup of 30 isolated ascending aortic repairs; by removing these outliers, the upper limits become less dramatic- $8.0 \%$ and $5.2 \%$, respectively. Iba et al's series, ${ }^{3}$ which had an overall mortality rate of $4.7 \%$ and a stroke rate of $3.5 \%$, may more accurately reflect actual contemporary open arch repair. Likewise, the risk associated with contemporary redo aortic arch repairs does not appear to be excessive; 30-day mortality rates range between $7.1 \%$ and $8.8 \% .^{6,7}$ Thus, it is hoped that reoperation alone does not classify a patient as high-risk. 
As present and future EAAR cases are further studied, EAAR may become an important option in the surgeon's armamentarium that is reserved for use in carefully selected patients at high risk for contemporary open aortic arch repair. To facilitate the selection of a personalized approach to arch repair, the addition and analysis of a composite end point in EAAR would be helpful in establishing which patients are best selected for this approach. In addition, a more comprehensive understanding of late events, including any compromise of landing zones in relation to chronic DeBakey type I dissection, is needed. By continuing to share their experiences-both good and bad-in the advancement of EAAR, these expert authors benefit both patients and clinicians.

The authors thank Stephen N. Palmer, PhD, ELS, of the Texas Heart Institute, for editorial assistance.

\section{References}

1. Haulon S, Greenberg RK, Spear R, Eagleton M, Abraham C, Lioupis C, et al. Global experience with an inner branched arch endograft. J Thorac Cardiovasc Surg. 2014;148:1709-16.

2. Lioupis C, Corriveau MM, MacKenzie KS, Obrand DI, Steinmetz OK, Abraham CZ. Treatment of aortic arch aneurysms with a modular transfemoral multibranched stent graft: initial experience. Eur J Vasc Endovasc Surg. 2012; 43:525-32.

3. Iba Y, Minatoya K, Matsuda H, Sasaki H, Tanaka H, Kobayashi J, et al. Contemporary open aortic arch repair with selective cerebral perfusion in the era of endovascular aortic repair. J Thorac Cardiovasc Surg. 2013;145:S72-7.

4. LeMaire SA, Price MD, Parenti JL, Johnson ML, Lay AD, Preventza O, et al. Early outcomes after aortic arch replacement by using the Y-graft technique. Ann Thorac Surg. 2011;91:700-8.

5. Moon MC, Morales JP, Greenberg RK. The aortic arch and ascending aorta: are they within the endovascular realm? Semin Vasc Surg. 2007;20:97-107.

6. Malvindi PG, van Putte BP, Sonker U, Heijmen RH, Schepens MA, Morshuis WJ. Reoperation after acute type a aortic dissection repair: a series of 104 patients. Ann Thorac Surg. 2013;95:922-7.

7. Moz M, Misfeld M, Leontyev S, Borger MA, Davierwala P, Mohr FW. Aortic arch reoperation in a single centre: early and late results in 57 consecutive patients. Eur J Cardiothorac Surg. 2013;44:e82-6. 